\title{
Restoration and Dynamic Pattern of Natural Herbaceous Vegetation of Xiangxi River's Water-Level Fluctuation Zone in the Three Gorges Reservoir Area
}

\author{
Jianxia Xu' ${ }^{1, a}$, Jianzhu Wang ${ }^{1, b}$, Bin $\mathrm{Lu}^{1, c^{*}}$, Heng Xie ${ }^{1, d}$, Lei $\mathrm{Li}^{1, \mathrm{e}}$ \\ Ming Wang ${ }^{1, f}$, Ziye Zheng ${ }^{1, g}$ \\ ${ }^{1}$ College of biological and pharmaceutical, China Three Gorges University, Yichang, Hubei, 443002, \\ China \\ a529438648@qq.com , bwangjianzhu@126.com, ${ }^{\mathrm{c}}$ 283028264@qq.com \\ d1182696787@qq.com, e'120112891@qq.com, ${ }^{\dagger} 646054343 @ q q . c o m$, \\ 91306041023@qq.com
}

\begin{abstract}
Keywords: Three Gorges Reservoir Area, Water-level Fluctuation Zone, Species Diversity, Vegetation Restoration, vegetation dynamic.

Abstract: Taking the vegetation at the water-level-fluctuation zone(WLFZ) of Xiangxi River as the object of the research, we use the sampling method to study the composition of species, diversity of community and dynamic pattern in two years at different altitudes after the filling of the Three Gorges Dam Reservoir. The results showed that species richness presented a trend which increased with the increase of the altitude. The main plants are annual herbs, an average of 26 species, accounting for $66.2 \%$.Next were perennial herbaceous plants. Plants which belonged to gramineae and compositae form a community of absolute advantage in this area. In general, plant are patchinesses or banded concentration distribution. With the elevation increasing, $\alpha$ and $\beta$ diversity increased. And the whole kinds of species would tend to be stable gradually in the WLFZ of Xiangxi River.
\end{abstract}

\section{Introduction}

Since the completion of the Three Gorges Dam, it has formed a 30-metre-high WLFZ along both sides of reservoir banks. Because of the operation mode which the clean water is harvest while the muddy one is not, the seasons when water fluctuates in the Three Gorges Reservoir is contrary to that in natural rivers. The WLFZ has been the ecologically weakest area in river banks. And it badly restricts the succession and development of surroundings of the reservoir[2]. Being the producer as well as the main founder and member of the landscape in the reservoir, vegetation has a high productivity and biomass. It can provide animals and human beings with habitat and material and energy. At the same time, the WLFZ has a function of corridor. It will be beneficial to the migration of animals which live both in water and on land. Besides, it has many functions such as preventing water and soil erosion, greening and beautifying landscape of river banks, reducing water pollution. Therefore, researches on the recovery and dynamic pattern of natural vegetation in the Three Gorges Reservoir area can provide a scientific basis for its ecological restoration.

\section{General situation of the area being surveyed}

Xiangxi River, the first branch of the Three Gorges, is located in $110^{\circ} 25^{\prime} 06^{\prime} \mathrm{E} \sim 111^{\circ} \mathrm{E}, 30^{\circ} 57$ 'N $31^{\circ} 34 \mathrm{~N}^{\prime}$. The total length of it is $94 \mathrm{~km}$. And the basin area is $3099 \mathrm{~km}^{2}$. The basin belongs to the sub-tropical continental monsoon climate. There are Rolling hills. The vertical variation of climate is significant, so is the microclimate. And the vertical distribution of vegetation is obvious.

\section{Methods}

According to the water level regulation scheme of three gorges reservoir(refer with: Fig. 1 ), On August 20-24, 2013 and August 18-22, 2014, we set 26 sample plots from the estuary of Xiangxi 
river to Gaoyang. In each plot, we set 3 transects by altitude(A:145 155m; B: 155 165m; $\mathrm{C}: 165 \sim 175 \mathrm{~m})$ to survey the vegetation. Since the main plants in this area were herbs, the quadrats were set to $1 \mathrm{~m}^{2}(1 \mathrm{~m} * 1 \mathrm{~m})$. In each transect, we set 5 quadrats according to "S". The total is 390 (26 plots $x 3$ transects x 5 quadrats, The plots distribution is shown in Fig.2). Write down the names of the plants, their hights, coverage and the number of each plant in every quadrat.

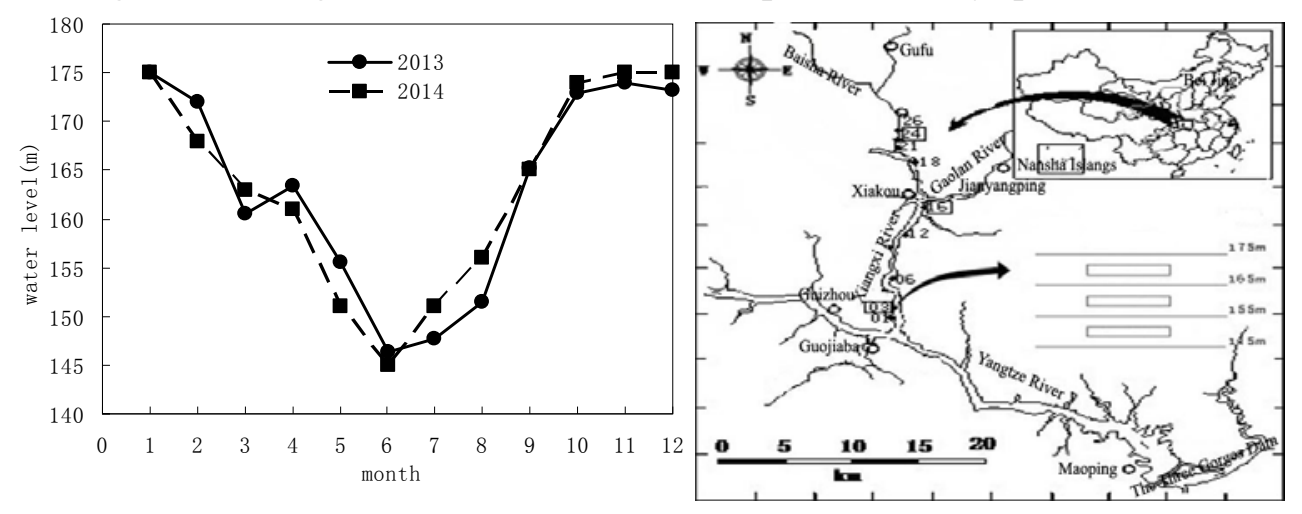

(Fig.1)

(Fig.2)

Fig. 1 The changes water level in 2013 and 2014 of the Three Gorges reservoir

Fig.2 The area being studied and the sampling sites (black dots represent sampling sites)

\section{Data Processing and Statistic Analysis}

(1) The calculation of relatively important value of each species in community Important value $=($ relative frequency + relative coverage + relative density $) / 3$

(2) $\alpha$ diversity index of community:

Patrick index, Simpson index, Shannon wiener index and Pielou index.[3]

(3) $\beta$ diversity index of community:

Cody index $(\beta c)$, Wilson Shmida index $(\beta T) \cdot[4]$

(4) Data analysis

SPSS 17.0 is used to do one way ANOVA to analyse the significance of datas from different altitude.

The significance level is $0.05(\alpha=0.05)$. Sigmaplot 10.0 is used to draw the charts.

\section{Results and Analysis}

Species composition of the WLFZ in Xiangxi River. According to field investigation and statistics, there were 39 kinds of plants, which belong to 37 genera and 20 families, distributed in the three different evelations in Xiangxi River hydro-fluctuation belt in 2013. The general which had more kinds of plants were Gramineae, Compositae, and Polygonaceae. According to the growth cycle, the number of annual herb was 27 , accounting for about $69.23 \%$. While in 2014 , there were 38 kinds of plants belonging to 16 genera and 35 families. The genera which had more kinds of plants were still Gramineae, Compositae and Polygonaceae. There were 24 annual herbs, accounting for about 63.16\%. Compared with 2013, Labiatae and cucurbitaceae occurred; however, Euphorbiaceae, Caryophyllaceae and Comfrey disappeared. The life form spectrum based on Raunkiaer life form classification data(Fig.3)showed that the main plants were annual herbs; next were cryptophytes. Phanerophytes were the shrubs that returned to green after the water levels fell. 

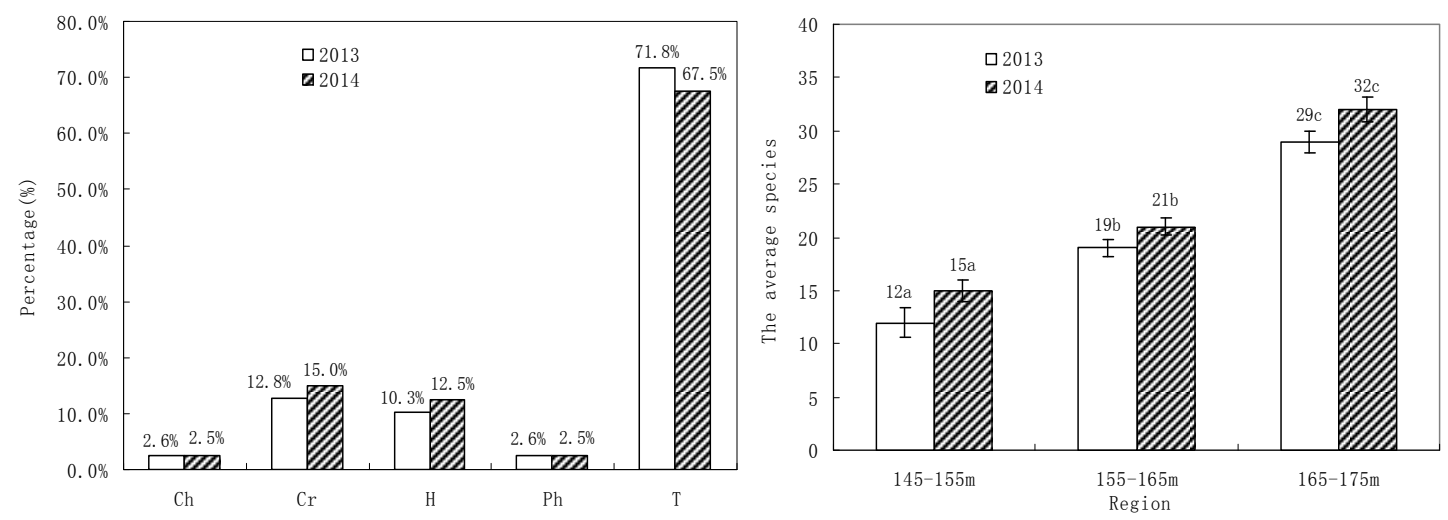

(Fig.4)

(Fig.3)

Fig .3 C. Raunkiaer life-form spectra of plant in Xiangxi River's water-level fluctuation zone. (Ph-phaenerophyte; Ch-chamaephyte; H-hemicryptophyte; Cr-geophyte; T-therophyte ;)

Fig .4 The species richness index (S) of the water-level fluctuation zone of the Xiangxi River .Different letters indicate significant at the 0.05 level.

a Species Diversity.The field investigation suggested that the number of species at 145 155 region, 155 165 region, 165 175 region were 12, 19 and 29 in Xiangxi River in 2013 respectively. While in 2014, the number of that were 15, 21 and 32 respectively. This indicated that the number of species increased significantly with the increasing of the water level gradient( $p<0.05)($ Fig.4). Species appearance frequency was largely in line with Raunkiaer laws of frequency. The frequency below $40 \%$ (A and B) account over $80 \%$ of all species in 2013; There were no species that frequencies were over $80 \%(\mathrm{E})$ in 2014(Fig.5). The Shannon-wiener diversity index and Pielou evenness index both increased with the increasing of elevation in 2013 and 2014, however dominance Simpson index declined in 2013(Fig.6) and no significant difference in 2014((p>0.05)
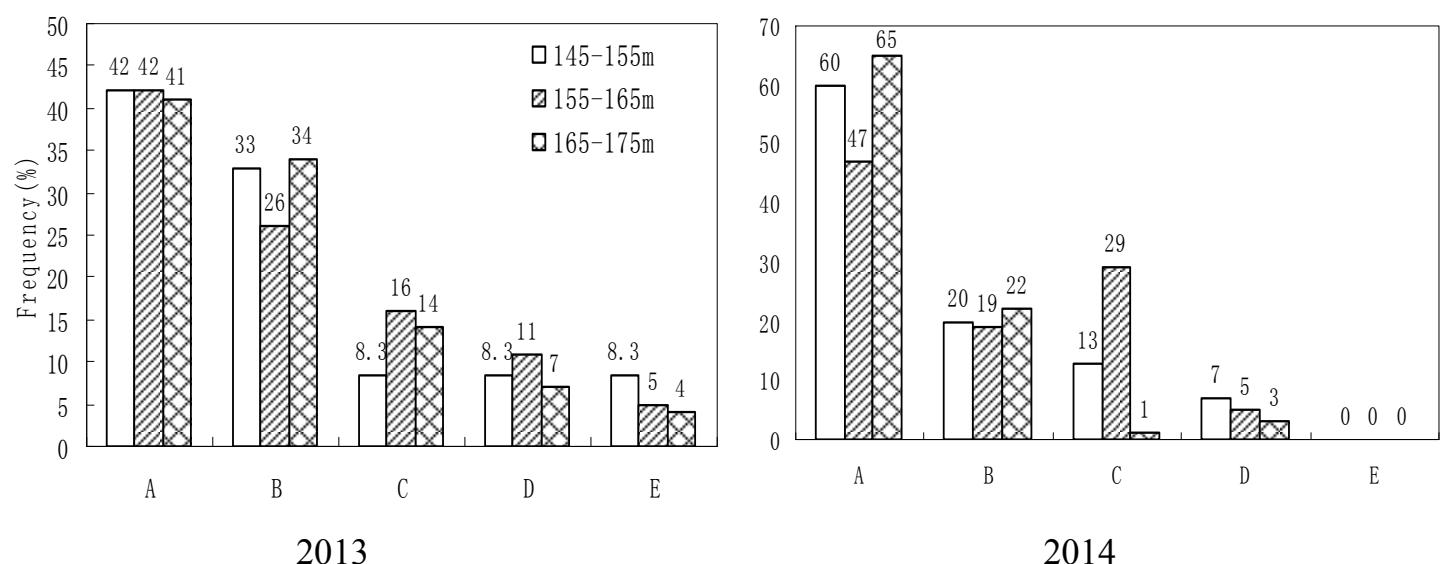

Fig. 5 Species and their Raunkiaer frequency pattern

Note: A: 1\%-20\% of frequency;B:21\%-40;C:41\%-60\%;D:61\%-80\%;E:81-100\%;
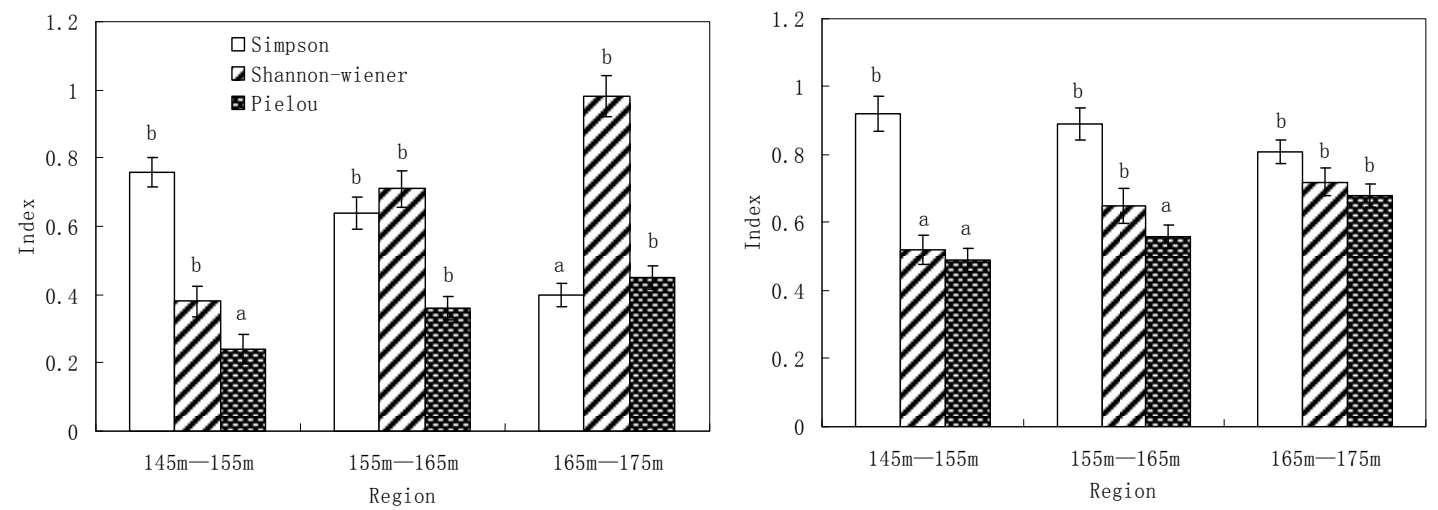

2013

Fig. 6 The $\alpha$-diversity of communities along elevat 
及 Species Diversity. In 2013 and 2014, plant community Cody index ( $\beta$ c), Wilson Shmida index $(\beta T)$ showed the trend of increasing with the increase of elevation in WLFZ of Xiangxi River (Fig.7). Cody index rising trend on the whole. This showed that the basic restoration process of vegetation in WLFZ is the increase of the kinds of plants, the reduction of commom species and the increase of $\beta$ diversity between communities. $\beta$ T index mainly reflects the differences of species composition. The increase of $\beta \mathrm{T}$ index indicated that there existed greater difference between the upper and lower of WLFZ.
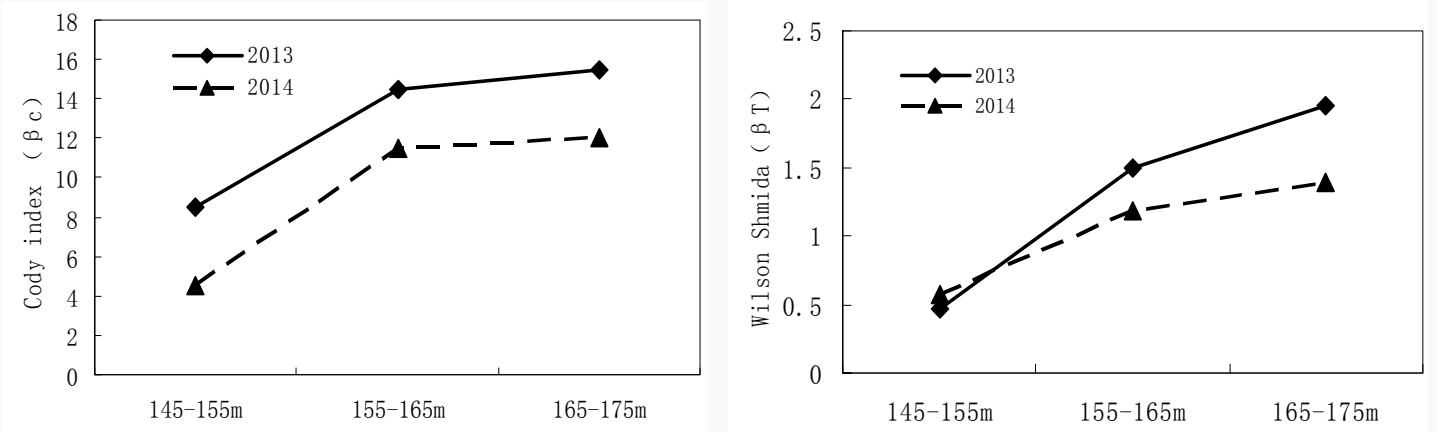

Fig. 7 Binary attribute data matrix of $\beta$-diversity index in the water-level

fluctuation zone in Xiangxi River

\section{Discussion}

Two years' research indicated that plant species composition was very simple, and Gramineae and compositae were dominat plants. $\beta$ diversity can not only reflect the difference of the species composition along the environmental gradient in different habitat communities, but also can reflect the replacement rate of the species along the environment gradient, therefore $\beta$ diversity can also be called the between-habitat diversity. Data differences of $\beta$ diversity in two years showed that three habitat gradients was formed due to the influence of fluctuation of water table in Xiangxi River hydro-fluctuation belt, namely 145 155m region, 155 165m region, 165 175m region。

The natural vegetation was mainly composed of annual herbaceous plants in field conditions. The results was similar with wang qiang et al[5]in Baijia River and consistent with Lu Zhijun et al[6] about the prediction of plants in hydro-fluctuation belt. Cynodon dactylon (Linn.) Pers. (Important value IV, 70.50\%) and Cyperus rotundus Linn. (Important value IV, 10.80\%) were the prominent dominant population in $145 \sim 155 \mathrm{~m}$ region, which was correlated with the resistance to water stress, drought tolerance, resistance to infertility and the degree of the developed root system. However, Annual herb plants, such as Setaria viridis (Linn.) Beauv. and Digitaria sanguinalis (Linn.) Scop. were mainly distributed in $145 \sim 175 \mathrm{~m}$ region. There were no significant distribution regularities to others.

Community evenness were proportional to A level and E level in Raunkiaer laws of frequency, which meant that Higher E level was accompanied with the higher community evenness. data for two years showed the low percentage of E level community, which indicated the simple species composition, species of the uneven distribution of vegetation community and low stability in hydro-fluctuation belt. Therefore the results implied that Cynodon dactylon and Cyperus rotundus will be the dominated species in the future in hydro-fluctuation belt.

\section{Conclusion}

1) Influenced by the change of water level, there formed three environmental gradient in the WLFZ of Xiangxi River, namely $145 \sim 155 \mathrm{~m}$ area, $155 \sim 165 \mathrm{~m}$ area, $165 \sim 175 \mathrm{~m}$ area.

2) The plants in WLFZ of Xiangxi River mainly compose of annual herb, secondly Perennial herb. The plant community distributes as concentrated patches or ribbon; Cynodon dactylon (Linn.) Pers.and Cyperus rotundus Linn. formed absolute dominant community in the 145-165m region. 
And annual herb such as Setaria viridis (Linn.) Beauv. and Digitaria sanguinalis (Linn.) Scop. mainly distributed upon elevation in $155 \sim 175 \mathrm{~m}$ section.

3 ) With the increase of elevation, $\alpha$ diversity index increased. And species uniformity increased too. $\beta$ diversity also increased; common species were few; and the succession of community was slow.

4) Two years' research indicated that the diversity of species in WLFZ of Xiangxi River tended to be stable after a long period of water flooding; and the species tend to simplification. This was closely related to the way species breed and their ability to resist water flooding.

\section{Acknowledgement}

This research is supported by grants including two NSFC projects toJZ(No. 51179094) and JZ (No. 30700091), and supported by Start-up Fund for Doctors in China Three Gorges University.

\section{References}

[1] Liang FQ.The Protection and Utilization of the Water-level-fluctuating Zone in the Three Gorges Reservoir of the Yangtze River .Wetland Research,6:326-329.(2002) (in Chinese)

[2] Tu JJ, Chen ZJ, Chen GJ, Li DQ.A Study on Consolidation and Utilization of the Water-level-fluctuating Zone in the Three Gorges Reservoir .Journal of Mountain Science, 20:712-717. (2002) (in Chinese)

[3] Ma KP,Huang JH, Yu SL, Chen LZ. Plant community diversity in Dongling mountain,Beijing,China,II species richness evenness and species diversities.Acta Ecologica Sinica,3:268-277. (1995) (in Chinese)

[4] Gao XM.Ma KP.Huang JH.Liu CR.Studies on plant community diversity in Dong lingshan Mountain, Beijing, China:xl. The $\beta$ diversity of mountainmeadow. Acta Ecologica Sinica.18.24-32. (1998) (in Chinese)

[5] Wang Q,Liu H,Yuan XZ,Sun R,Wang JX. Patternand Biodiversity of Plant Community in Water-Level-Fluctuation Zone of Pengxi River After Impoundment of Three Gorges Reservoir.Journal of Chongqing Normal University(Natural Science).4.48-54. (2009) (in Chinese)

[6] Lu ZJ, Li LF, Huang HD,Tao M,Zhang QF,Jiang XM.Prelim inary Effects of Impounding on Vegetation in Drawdown Zone of the Three Gorges Reservoir Region.Journal of Wuhan Botanical Research, 28 : 303 314. (2010) (inChinese) 